\title{
Epinephrine and short-term survival in cardiogenic shock : an individual data meta-analysis of 2583 patients
}

\section{Leopold, Valentine}

2018-06

Leopold, V , Gayat , E , Pirracchio , R , Spinar , J , Parenica , J , Tarvasmäki , T , Lassus , J , Harjola , V-P , Champion, S, Zannad , F, Valente , S, Urban , P , Chua, H-R , Bellomo , R, Popovic , B , Ouweneel , D M , Henriques , J P S , Simonis , G , Levy , B , Kimmoun , A , Gaudard , P , Basir , M B , Markota , A , Adler , C, Reuter , H, Mebazaa , A \& Chouihed , T 2018 , ' Epinephrine and short-term survival in cardiogenic shock : an individual data meta-analysis of 2583 patients ' , Intensive Care Medicine , vol. 44 , no. 6 , pp. 847-856 . https://doi.org/10.1007/s00

http://hdl.handle.net/10138/303660

https://doi.org/10.1007/s00134-018-5222-9

publishedVersion

Downloaded from Helda, University of Helsinki institutional repository.

This is an electronic reprint of the original article.

This reprint may differ from the original in pagination and typographic detail.

Please cite the original version. 


\title{
SYSTEMATIC REVIEW
}

\section{Epinephrine and short-term survival in cardiogenic shock: an individual data meta-analysis of 2583 patients}

Valentine Léopold ${ }^{1}$, Etienne Gayat ${ }^{1}$, Romain Pirracchio ${ }^{2}$, Jindrich Spinar ${ }^{3}$, Jiri Parenica ${ }^{3}$, Tuukka Tarvasmäki ${ }^{4,5}$, Johan Lassus ${ }^{4}$, Veli-Pekka Harjola4, Sébastien Champion ${ }^{6}$, Faiez Zannad7', Serafina Valente ${ }^{8}$, Philip Urban ${ }^{9}$, Horng-Ruey Chua ${ }^{10,11,12,13,14}$, Rinaldo Bellomo ${ }^{10,11,12,13}$, Batric Popovic ${ }^{15}$, Dagmar M. Ouweneel ${ }^{16}$, José P. S. Henriques ${ }^{16}$, Gregor Simonis ${ }^{17,18}$, Bruno Lévy ${ }^{19}$, Antoine Kimmoun ${ }^{19}$, Philippe Gaudard ${ }^{20}$, Mir Babar Basir ${ }^{21}$, Andrej Markota ${ }^{22}$, Christoph Adler ${ }^{23}$, Hannes Reuter ${ }^{23}$, Alexandre Mebazaa 1,24* and Tahar Chouihed $1,7,25,26$

\begin{abstract}
Objective: Catecholamines have been the mainstay of pharmacological treatment of cardiogenic shock (CS). Recently, use of epinephrine has been associated with detrimental outcomes. In the present study we aimed to evaluate the association between epinephrine use and short-term mortality in all-cause CS patients.

Design: We performed a meta-analysis of individual data with prespecified inclusion criteria: (1) patients in non-surgical CS treated with inotropes and/or vasopressors and (2) at least 15\% of patients treated with epinephrine administrated alone or in association with other inotropes/vasopressors. The primary outcome was short-term mortality.

Measurements and results: Fourteen published cohorts and two unpublished data sets were included. We studied 2583 patients. Across all cohorts of patients, the incidence of epinephrine use was 37\% (17-76\%) and short-term mortality rate was $49 \%$ (21-69\%). A positive correlation was found between percentages of epinephrine use and short-term mortality in the CS cohort. The risk of death was higher in epinephrine-treated CS patients $(\mathrm{OR}[\mathrm{Cl}]=3.3$ [2.8-3.9]) compared to patients treated with other drug regimens. Adjusted mortality risk remained striking in epinephrine-treated patients ( $n=1227$ ) (adjusted $O R=4.7$ [3.4-6.4]). After propensity score matching, two sets of 338 matched patients were identified and epinephrine use remained associated with a strong detrimental impact on short-term mortality $(\mathrm{OR}=4.2$ [3.0-6.0]).
\end{abstract}

Conclusions: In this very large cohort, epinephrine use for hemodynamic management of CS patients is associated with a threefold increase of risk of death.

Keywords: Meta-analysis, Cardiogenic shock, Epinephrine, Prognosis

*Correspondence: alexandre.mebazaa@aphp.fr

${ }^{1}$ Department of Anesthesiology and Critical Care, APHP - Saint Louis Lariboisière University Hospitals, University Paris Diderot and INSERM UMR-S 942, Paris, France

Full author information is available at the end of the article

Valentine Léopold and Etienne Gayat are co-first authors.

Alexandre Mebazaa and Tahar Chouihed are co-last authors.

\section{Introduction}

Cardiogenic shock (CS) is a state characterized by acute cardiac failure leading to low cardiac output, hypotension, and end-organ hypoperfusion [1]. CS is mostly related to acute coronary syndrome (ACS) and its mortality remains high despite improvements in ACS revascularization therapies [2]. The pharmacologic treatment 
of CS may require the combination of vasopressor therapy to restore and maintain systemic blood pressure and/ or inotropic support to improve cardiac output. Hence, agents such as epinephrine and norepinephrine have been recommended owing to their cardiac and/or vascular benefits via alpha- and beta-adrenergic receptor stimulation $[3,4]$.

However, the use of catecholamines in acute heart failure may be associated with higher short- and long-term mortality [5, 6]. Among catecholamines, retrospective analyses have linked the need for epinephrine to worse outcome in patients with myocardial infarction or treated with mechanical circulatory support $[7,8]$. More recently, data from a prospective patient cohort [9] and two small randomized trials $[10,11]$ suggest that in cardiogenic shock, epinephrine might be associated with detrimental short-term outcome.

Accordingly, we performed a systematic review of all studies assessing cardiogenic shock treatment and shortterm mortality using individual patient data. Across multiple cohorts with varying prevalence of epinephrine use and mortality, we sought to evaluate the association between epinephrine use and short-term outcome in CS. We hypothesized that epinephrine use was associated with a higher mortality compared to other inotrope(s) and/or vasopressor(s) regimen in cardiogenic shock patients.

\section{Methods}

\section{Search strategy and selection of articles}

We performed a systematic search of MEDLINE, Cochrane, and Web of Science databases using the following detailed search terms: Adrenaline, Epinephrine, Catecholamines, Vasopressors, Inotropes, and Cardiogenic shock, excluding articles in a language other than English, published prior to January 1, 1995, and case reports. The prespecified keyword combination used to run the literature search was "Adrenaline"[All Fields] OR "Epinephrine"[MeSH Terms] OR "Epinephrine"[All fields] OR "Catecholamines"[MeSH Terms] OR "Catecholamines"[All Fields] OR "Vasopressors"[All Fields] OR "Inotropes"[All Fields]) AND ("Shock, Cardiogenic"[MeSH Terms] OR "cardiogenic shock"[Title]) AND (("1995/01/01"[PDAT]: “2017/11/01"[PDAT]) AND English[lang]) NOT “case reports"[Publication Type]. The last search was performed on November 11, 2017 (Fig. 1). Studies were included if they met the following prespecified inclusion criteria: (1) patients in cardiogenic shock treated with inotropes and/or vasopressors excluding postoperative CS and (2) at least $15 \%$ of patients of each study should have been treated with epinephrine used alone or in association with other inotropes/vasopressors. All findings are reported in accordance with the Preferred Reporting Items for Systematic Review and Meta-analysis of Individual Participant Data (PRISMA-IPD) [12]. The quality of the included studies was assessed using the Newcastle-Ottawa scale [13].

\section{Data extraction}

Two investigators (V.L. and T.C.) performed the initial screening of titles and abstracts. Full-text reports of potentially relevant articles were obtained and assessed by both investigators using a prespecified protocol (PROSPERO Registration Number CRD42017082370). Two investigators (E.G. and A.M.) adjudicated all disagreements. Corresponding author(s) of each eligible cohort were contacted with a request for anonymized individual data sets and prespecified covariates: age, sex, medical history, systolic and diastolic blood pressure (SBP/DBP), heart rate (HR), left ventricular ejection fraction (LVEF), Acute Physiology and Chronic Health Evaluation II (APACHE II), Sepsis-related Organ Failure Assessment (SOFA), cause of CS, mechanical support [defined as extracorporeal life support (ECLS) or Impella; and ECLS defined as extracorporeal membrane oxygenation (ECMO) or left ventricular assist device (LVAD)], lactate, estimated glomerular filtration rate (eGFR), BNP or NT-proBNP, and troponin. All studies were conducted in accordance with the Declaration of Helsinki with approval from the regional ethics committee or institutional review board.

\section{Analysis population and primary outcome}

The analysis population comprised patients with all causes of CS treated with epinephrine versus others catecholamines. Patients who presented post cardiac arrest were included in the analysis. The prespecified primary outcome was short-term mortality whether at 28 or 30 days, during ICU or hospital stay. The number of patients available for analysis is shown in Table 1.

\section{Statistical analysis}

Data were expressed as median and quartiles for continuous variables and numbers and percentages for nominal variables. The main outcome measure was short-term mortality. The analysis of the combined data was conducted using Metafor Package and the R statistical software [14].

One purpose of the present study was to conduct metaregression to assess the relation between mortality rate and the rate of epinephrine use. A linear mixed-effect model was used to assess association. Random-effects models were used for the meta-analysis of the effect of epinephrine on mortality. Results were summarized as odds ratio (OR) with $95 \%$ confidence interval 


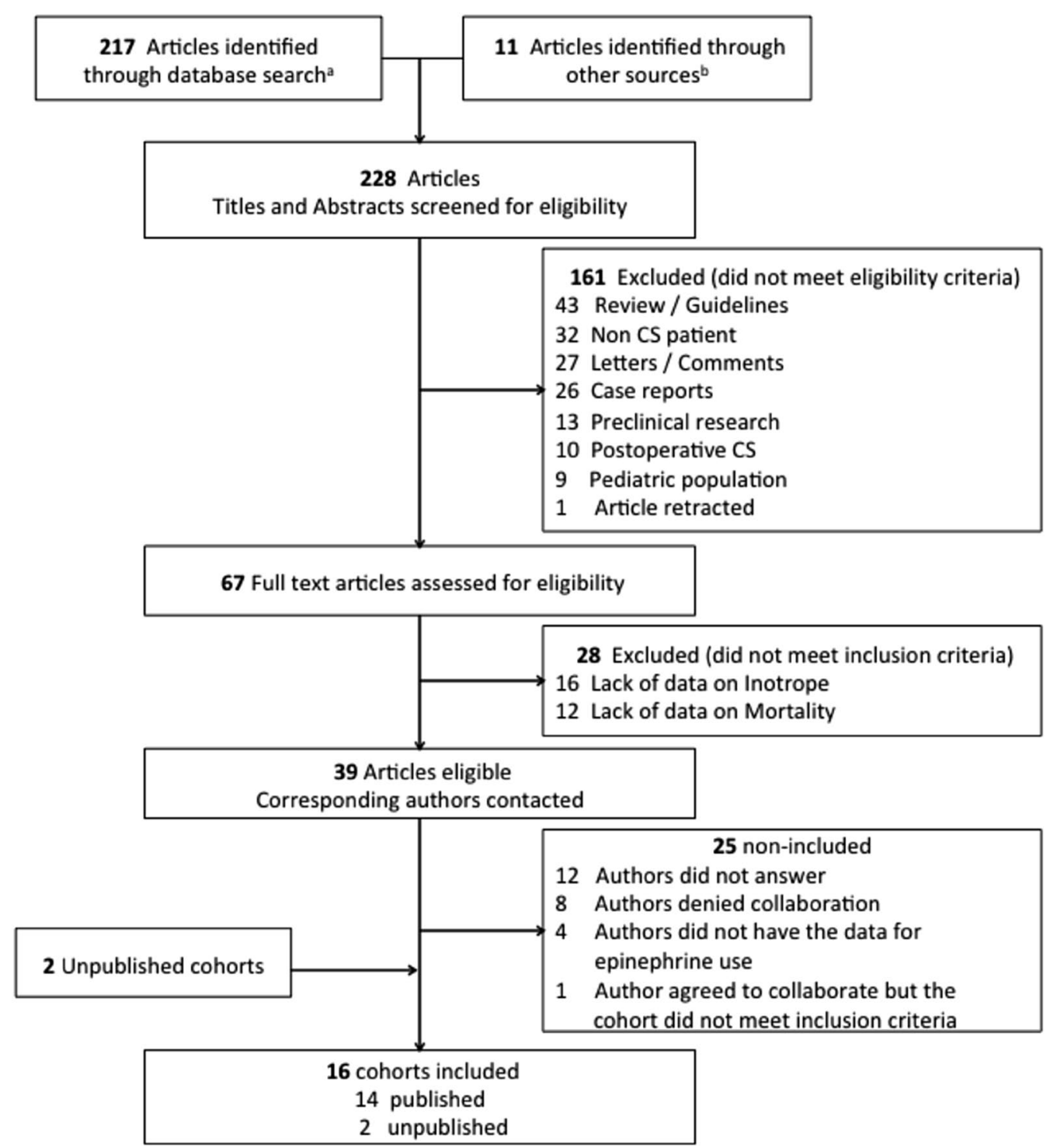

Fig. 1 Flow diagram illustrating the systematic database review and screening of articles, level of exclusion, number of articles included. Based on the PRISMA-IPD guidelines. ${ }^{\mathrm{a} A r t i c l e s ~ i d e n t i f i e d ~ t h r o u g h ~ a ~ s y s t e m a t i c ~ d a t a b a s e ~ s e a r c h: ~ M E D L I N E ~} n=191$; Cochrane $n=26 .{ }^{\mathrm{b}}$ Articles identified through supplemental research targeting experts on cardiogenic shock

(95\% CI). Adjustment for main prognostic variables (age, gender, ischemic heart disease, eGFR, and LVEF at admission) was also considered. Moreover, given the observational nature of the data, treatment allocation was not randomly allocated in the study population. The risk of allocation bias due to the presence of confounders was handled using propensity score (PS) matching [15]. Using PS matching, we could estimate the causal effect of the exposure on the outcome more precisely assuming a set of identifiability and causal assumptions. The PS was estimated from the observed data using a logistic regression model including a set of variables selected among available baseline variables (age, gender, LVEF, ACS as cause of CS, eGFR, HR, and low blood pressure). Each patient treated with epinephrine was matched to one untreated control with similar PS using the nearest-neighbor approach, with no replacement and a caliper size of 0.15 . In this approach, each treated subject was matched to the nearest untreated subject within a specified maximum difference in the PS between two matched subjects (so-called caliper). Covariate balance between the two groups before and after PS matching was assessed using the mean standardized differences (MSD). An absolute MSD less than $10 \%$ was considered 
Table 1 Sample size, inclusion criteria, outcome and main patients' characteristics in all the studies included

\begin{tabular}{|c|c|c|c|c|c|c|c|c|}
\hline $\begin{array}{l}\text { Observational } \\
\text { studies }\end{array}$ & $\begin{array}{l}\text { Inclusion } \\
\text { period }\end{array}$ & $\begin{array}{l}\text { Cause of car- } \\
\text { diogenic shock }\end{array}$ & $\begin{array}{l}\text { Single/multi- } \\
\text { center }\end{array}$ & $\begin{array}{l}\text { Number } \\
\text { of patients ( } n \text { ) }\end{array}$ & $\begin{array}{l}\text { Epinephrine- } \\
\text { treated } \\
\text { patients } n(\%)\end{array}$ & Death $n(\%)$ & $\begin{array}{l}\text { Mortality } \\
\text { endpoint }\end{array}$ & $\operatorname{ECLS}(n)$ \\
\hline Adler, 2012 [16] & 2007-2008 & $\begin{array}{l}\text { Out of hospital } \\
\text { cardiac arrest }\end{array}$ & Single & 40 & $10(25)$ & $11(28)$ & Day 30 & No \\
\hline Adler, unpublished & & All-cause & Single & 47 & $9(19)$ & $10(21)$ & Day 30 & No \\
\hline AHEAD, 2011 [17] & 2006-2009 & All-cause & Multi & 674 & $304(45)$ & $469(69)$ & Day 30 & No \\
\hline ALARM, 2011 [5] & 2006-2007 & All-cause & Multi & 520 & $86(17)$ & $215(41)$ & Day 30 & No \\
\hline Basir, 2018 [35] & 2016 & $\begin{array}{l}\text { Acute coronary } \\
\text { syndrome }\end{array}$ & Single & 45 & $8(18)$ & $31(69)$ & In-hospital & No \\
\hline $\begin{array}{l}\text { CARDSHOCK, } 2016 \\
\text { [9] }\end{array}$ & 2010-2012 & All-cause & Multi & 219 & $46(21)$ & $80(37)$ & Day 30 & Yes (8) \\
\hline Champion, 2014 [18] & 2012-2014 & All-cause & Single & 192 & $130(68)$ & $93(48)$ & In-hospital & Yes (15) \\
\hline Chua, 2012 [19] & 2008-2011 & $\begin{array}{l}\text { Out of hospital } \\
\text { cardiac arrest }\end{array}$ & Single & 105 & $80(76)$ & $46(43)$ & In-hospital & No \\
\hline EFICA, 2006 [20] & $2001-2001$ & All-cause & Multi & 158 & $75(48)$ & $87(55)$ & Day 30 & No \\
\hline Gaudard, 2015 [21] & 2008-2013 & All-cause & Single & 40 & $11(28)$ & $14(35)$ & Day 28 & Yes (17) \\
\hline Popovic, 2014 [22] & 2007-2011 & $\begin{array}{l}\text { Acute coronary } \\
\text { syndrome }\end{array}$ & Single & 86 & $47(55)$ & $37(43)$ & In-ICU & No \\
\hline Valente, 2012 [23] & 2004-2009 & All-cause & Single & 152 & $34(22)$ & $71(46)$ & $\ln -\mathrm{ICU}$ & Yes (3) \\
\hline \multicolumn{9}{|c|}{ Randomized controlled trials - intervention other than inotrope(s) and/or vasopressor(s) effect } \\
\hline $\begin{array}{l}\text { IMPRESS in severe } \\
\text { shock, } 2017 \text { [24] }\end{array}$ & 2012-2015 & $\begin{array}{l}\text { Acute coronary } \\
\text { syndrome }\end{array}$ & Multi & 48 & $14(29)$ & $23(47)$ & Day 30 & Yes (2) \\
\hline Simonis, 2012 [25] & $2007-2009$ & All-cause & Single & 89 & $25(28)$ & $31(34)$ & Day 30 & No \\
\hline SMASH, 1999 [26] & 1992-1996 & $\begin{array}{l}\text { Acute coronary } \\
\text { syndrome }\end{array}$ & Multi & 111 & $41(37)$ & $34(30)$ & Day 30 & Yes (9) \\
\hline \multicolumn{9}{|c|}{ Randomized controlled trial_-epinephrine versus norepinephrine } \\
\hline \multirow[t]{2}{*}{$\begin{array}{l}\text { OPTIMA CC, } 2018 \\
\text { [11] }\end{array}$} & $2011-2016$ & $\begin{array}{l}\text { Acute coronary } \\
\text { syndrome }\end{array}$ & Multi & 57 & $27(47)$ & $21(37)$ & Day 30 & Yes (3) \\
\hline & & & Total & 2583 & $947(37)$ & $1273(49)$ & & \\
\hline
\end{tabular}

ECLS extracorporeal life support (combining extracorporeal membrane oxygenation (ECMO) and left ventricular assist devices (LVAD))

to support the assumption of balance between the groups. Subgroups analyses were also considered. In particular, the population was dichotomized according to median value of LVEF, natriuretic peptides, and troponin levels. To take into account intercenter variability regarding the measurement of those three continuous parameters, median values used for the dichotomization were assessed within each center. All statistical analyses were performed using $\mathrm{R}$ statistical software with the statistical package MatchIt for the matching process ( $R$ Foundation for Statistical Computing, Vienna, Austria; http://www. jstatsoft.org/v42/i08/).

\section{Results}

\section{Systematic review}

The initial search found 228 studies (Fig. 1), of which 67 were eligible for full text review and 39 studies were included. Authors consented to provide individual participant data from 14 published cohorts and 2 unpublished data sets.

Characteristics of the 16 included cohorts are described in Table 1 . Of note, 12 were observational cohorts $[5,9$, 16-23] and 4 were randomized controlled trials, but only one compared epinephrine and norepinephrine on outcome [11, 24-26]. The quality of the nonrandomized included studies was assessed using the NewcastleOttawa scale (Supplemental Table 1). The main characteristics of the 25 non-included cohorts are depicted in Supplemental Table 2 .

\section{Study population}

Individual patient-level data were obtained for a total population of 2583 patients with CS (Table 2) of which 462 (18\%) occurred after resuscitation of cardiac arrest. In our studied population of CS patients, the incidence of epinephrine use was $37 \%$, ranging from $17 \%$ to $76 \%$ across all cohorts, and epinephrine was the third most 
Table 2 Total population characteristics, $n=2583$

\begin{tabular}{|c|c|c|}
\hline & $\%$ of missing data & All included patients $(n=2583$ \\
\hline \multicolumn{3}{|l|}{ General characteristics } \\
\hline \multicolumn{3}{|l|}{ Age (years) } \\
\hline$<45$ & 2.2 & $172(7 \%)$ \\
\hline $45-60$ & & $563(22 \%)$ \\
\hline $60-70$ & & $675(26 \%)$ \\
\hline $70-80$ & & $730(29 \%)$ \\
\hline$>80$ & & $416(16 \%)$ \\
\hline Male gender & 2.1 & $1335(52 \%)$ \\
\hline Coronary artery disease & 16 & $1101(51 \%)$ \\
\hline Chronic heart failure & 32.1 & $582(33 \%)$ \\
\hline History of hypertension & 66.2 & $458(51 \%)$ \\
\hline Diabetes mellitus & 9.1 & $861(36 \%)$ \\
\hline Chronic kidney disease & 14 & $523(23 \%)$ \\
\hline \multicolumn{3}{|l|}{ Hemodynamic at admission } \\
\hline $\mathrm{SBP}(\mathrm{mmHg})$ & 17.8 & $90[80 ; 117]$ \\
\hline $\mathrm{MBP}(\mathrm{mmHg})$ & 71.6 & $65[55 ; 77]$ \\
\hline $\mathrm{DBP}(\mathrm{mmHg})$ & 78.6 & $50[41 ; 60]$ \\
\hline Heart rate (bpm) & 17.2 & $98[78 ; 118]$ \\
\hline LVEF (\%) & 32.7 & $30[20 ; 40]$ \\
\hline Cardiac arrest prior to admission & 67.9 & $462(53.8)$ \\
\hline \multicolumn{3}{|l|}{ Severity score } \\
\hline APACHE II & 80.4 & $41[27 ; 90.2]$ \\
\hline SOFA score & 91 & $10[9 ; 12]$ \\
\hline \multicolumn{3}{|l|}{ Cause of cardiognenic shock } \\
\hline Acute coronary syndrome & 9.3 & $1563(66)$ \\
\hline Post cardiac arrest & 61.7 & $456(45)$ \\
\hline Cardiomyopathy & 61.6 & $103(10)$ \\
\hline Myocarditis & 65.1 & $7(1)$ \\
\hline Endocarditis & 70.1 & $3(0)$ \\
\hline Takotsubo & 65.1 & $5(1)$ \\
\hline \multicolumn{3}{|l|}{ Biology at admission } \\
\hline Hemoglobin (g/dL) & 68.2 & $12.7[11.2 ; 14.5]$ \\
\hline Hematocrit (\%) & 86.4 & $40[35.5 ; 43]$ \\
\hline $\mathrm{eGFR}\left(\mathrm{mL} / \mathrm{min} / 1.73 \mathrm{~m}^{2}\right)$ & 19.4 & $64.8[43.5 ; 94.8]$ \\
\hline Creatinin $(\mu \mathrm{mol} / \mathrm{L})$ & 29.3 & $124[95 ; 173]$ \\
\hline Lactate $(\mathrm{mmol} / \mathrm{L})$ & 63.6 & $4.7[2.5 ; 9.3]$ \\
\hline Troponin (OR) & 77.7 & $75[4.5 ; 572]$ \\
\hline \multirow[t]{2}{*}{ Natriuretic peptide } & 79.9 & BNP: $1150[351 ; 2419]$ \\
\hline & & NT-proBNP: $3604[1069 ; 10,117]$ \\
\hline \multicolumn{3}{|l|}{ Treatment of cardiogenic shock } \\
\hline $\mathrm{PCl}$ & 63.0 & $516(54 \%)$ \\
\hline CABG & 67.3 & $36(4 \%)$ \\
\hline IABP & 9.9 & $676(29 \%)$ \\
\hline ECLS & 70.8 & $55(7 \%)$ \\
\hline Impella & 70.0 & $81(11 \%)$ \\
\hline Epinephrine & 0.0 & $947(37 \%)$ \\
\hline
\end{tabular}


Table 2 continued

\begin{tabular}{lll} 
& \% of missing data & All included patients $(\boldsymbol{n}=\mathbf{2 5 8 3})$ \\
\hline Norepinephrine & 13.8 & $1220(54 \%)$ \\
Dopamine & 21.4 & $557(27 \%)$ \\
Dobutamine & 9.3 & $1110(47 \%)$ \\
Levosimendan & 16.8 & $233(11 \%)$ \\
\hline
\end{tabular}

Detailed data for every study are given in Supplemental Table 3

$S B P$ systolic blood pressure, MBP mean blood pressure, DBP diastolic blood pressure, $L V E F$ left ventricular ejection fraction, eGFR estimated glomerular filtration rate, $P C I$ primary coronary intervention, $C A B G$ coronary artery bypass graft, IABP intra-aortic balloon pump, ICU intensive care unit

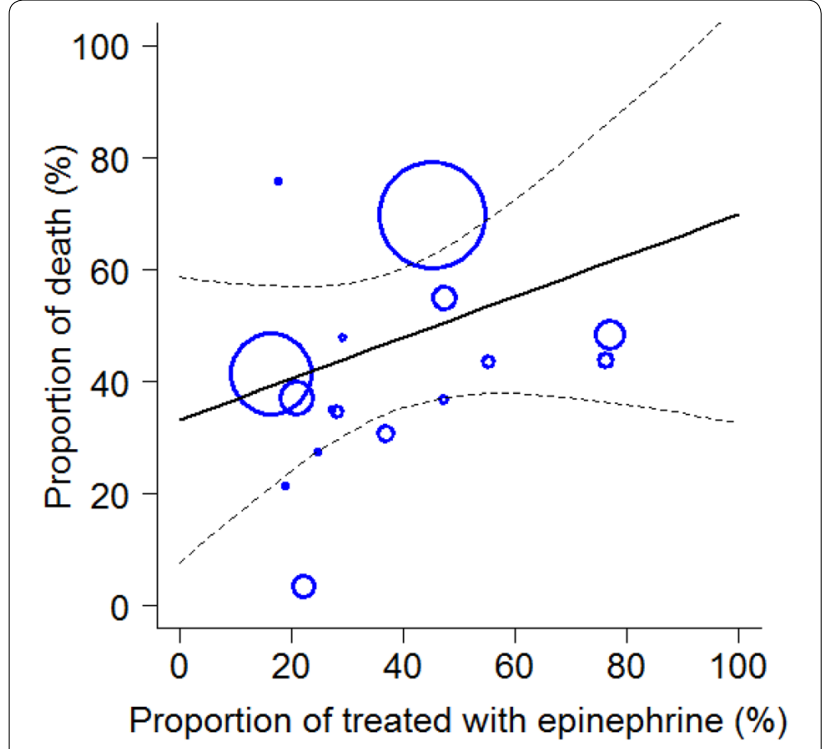

Fig. 2 Association between short-term mortality and the proportion of patients receiving epinephrine. Each circle represents one study. The radius of the circle is proportional to the cohort size

used catecholamine after norepinephrine (54\%) and dobutamine (47\%) (Supplemental Table 3). Short-term mortality rate was $49 \%$, ranging from $21 \%$ to $69 \%$. Figure 2 shows a correlation between the percentage of epinephrine use and short-term death by cohort.

\section{Epinephrine use and risk of short-term death}

Across all cohorts $(n=16)$, risk of short-term death was significantly higher in epinephrine-treated patients (OR $[\mathrm{CI}]=3.3[2.8-3.9])$ compared to patients treated with other drug regimens for CS (Fig. 3). Of note, among the 16 cohorts, the majority had positive risk of death associated with the use of epinephrine whether statistically significant $(n=6)$ or as a trend $(n=7)$.

Risk of short-term death with the use of epinephrine was also adjusted for age, gender, ischemic heart disease, eGFR and LVEF at admission in a subset of 1227 patients. The adjusted mortality risk remained striking in epinephrine-treated patients (adjusted OR $=4.7[3.4-$ 6.4]) (Fig. 4).

Furthermore, after propensity score matching, two sets of 338 matched patients balanced for all considered characteristics were identified (Supplemental Table 4) and epinephrine use was associated with a strong detrimental impact on short-term mortality $(\mathrm{OR}=4.2$ [3.0-6.0]).

Sensitivity analysis showed persistent detrimental association between epinephrine use and short-term mortality. After exclusion of the largest cohort (AHEAD), the OR was 2.3 [1.9-2.8], with a robust estimation of the standard error (model with cluster effect). Figure 5 confirms that epinephrine use was significantly associated in all subgroups (including patients with acute coronary syndrome) except those who benefited from ECLS (189/671 (28\%) without ECLS versus 58/124 (48\%) with ECLS, $p<0.0001)$.

\section{Discussion}

Using a large cohort of collaborative meta-analysis of allcause cardiogenic shock patients, we demonstrated that epinephrine use is associated with a striking excess in mortality compared to other drug regimens. The association remains robust even after adjustment and propensity score matching and was consistent in the majority of the studied cohorts.

Our meta-analysis of individual data shows that epinephrine is frequently used in CS regardless of the mechanisms of CS, including those not related to cardiac arrest. Our study further shows that the use of epinephrine in CS was associated with several-fold increase in short-term risk of death in crude, adjusted, or propensity score analysis. This excess of mortality is present in all subgroups, except among those who benefited from ECLS. Mechanisms of lack of detrimental association between epinephrine use and ECLS in CS remains elusive. They might be (1) related to early withdrawal of epinephrine in patients under ECLS and/or (2) less "detrimental" effect of epinephrine in hearts with reduced myocardial wall stress, and enhanced coronary perfusion [27]. We observed a low rate of ECLS (7\%) that might be 


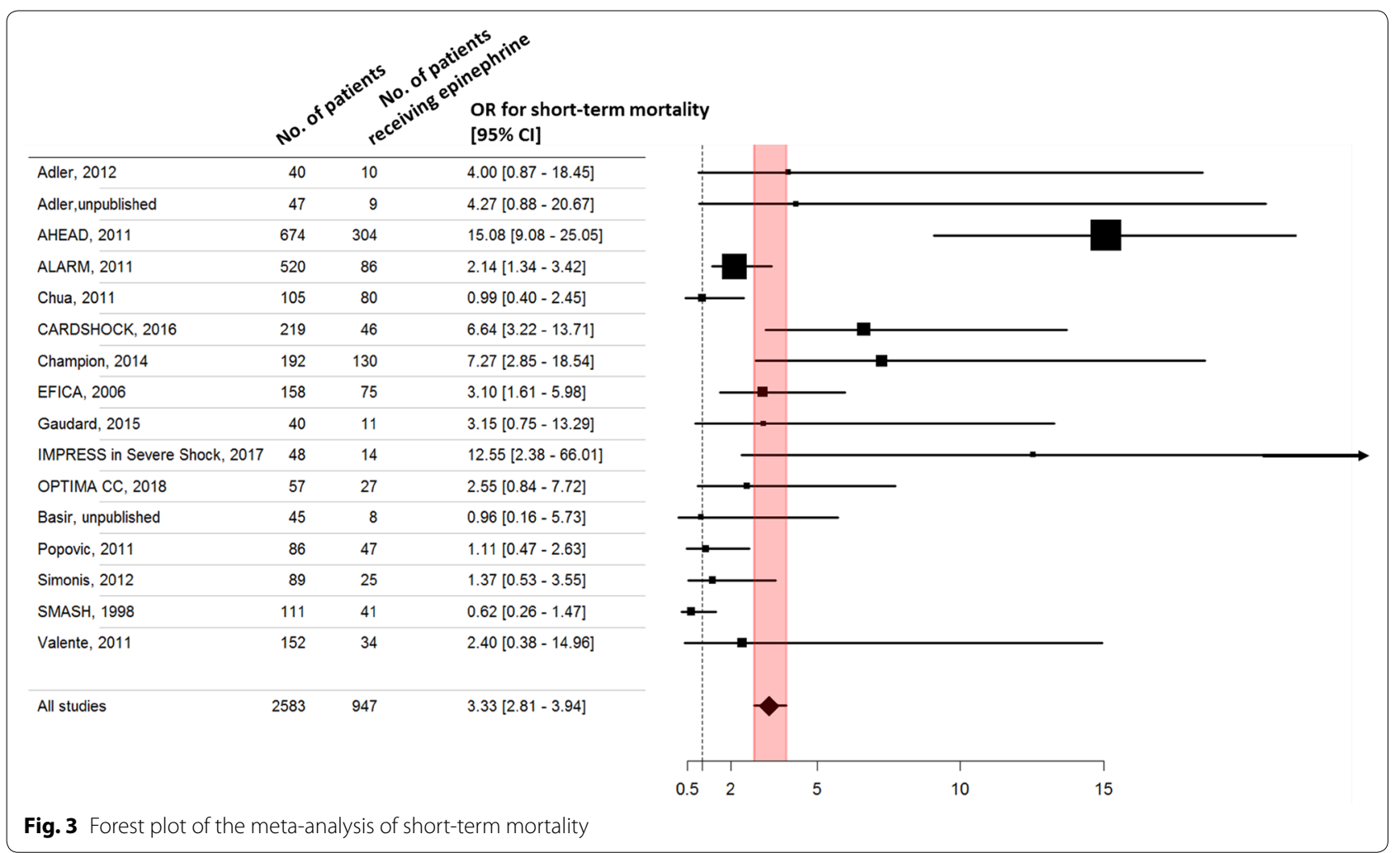

\begin{tabular}{|c|c|c|c|c|c|c|c|}
\hline & $\begin{array}{l}\text { No. of analyzed } \\
\text { patients }\end{array}$ & $\begin{array}{l}\text { OR for short-term } \\
\text { mortality [95\% Cl] }\end{array}$ & & & & & \\
\hline AHEAD excluded & 1909 & $2.29[1.88-2.78]$ & & & $\longrightarrow$ & & \\
\hline OPTIMA CC excluded & 2526 & $3.38[2.85-4.01]$ & & & & & \\
\hline Published cohorts only & 2491 & $3.40[2.87-4.03]$ & & & & & \\
\hline Cluster effect & 2583 & $3.74[3.07-4.56]$ & & & & & \\
\hline Fully adjusted & 1227 & $4.68[3.43-6.39]$ & & & & & \\
\hline \multirow[t]{3}{*}{ PS-matched } & 676 & $4.22[2.99-5.96]$ & & & & & \\
\hline & & & \ulcorner & & 1 & 1 & $\neg$ \\
\hline & & & 0.5 & 1 & 2 & 5 & 7.5 \\
\hline
\end{tabular}

explained by the recent increase in interest and use of mechanical support in cardiogenic shock management.

The mechanism of possible epinephrine toxicity remains unclear. Detrimental effects of epinephrine might be related to worsening of cardiac condition, despite hemodynamic benefits [2, 9, 28]. Epinephrine increases oxygen consumption and alters calcium homeostasis more than other catecholamine [29]. Hence, in CS where cardiac condition is already severely altered, epinephrine might markedly aggravate cardiac metabolism leading to death. Epinephrine may similarly affect metabolism in other organs as recently shown in the OPTIMA CC and Cardshock studies [9,11]. This may be due to epinephrine-induced alteration in microcirculation, specifically in the renal bed. These findings suggest that epinephrine's detrimental effect may be related to multiorgan toxicity [30-32].

Our meta-analysis indicates that in CS, the risk/benefit ratio favors the administration of inotropes and/ or vasopressors other than epinephrine. Hence, the use of norepinephrine alone or combined with an inotrope, including dobutamine or levosimendan, may be 


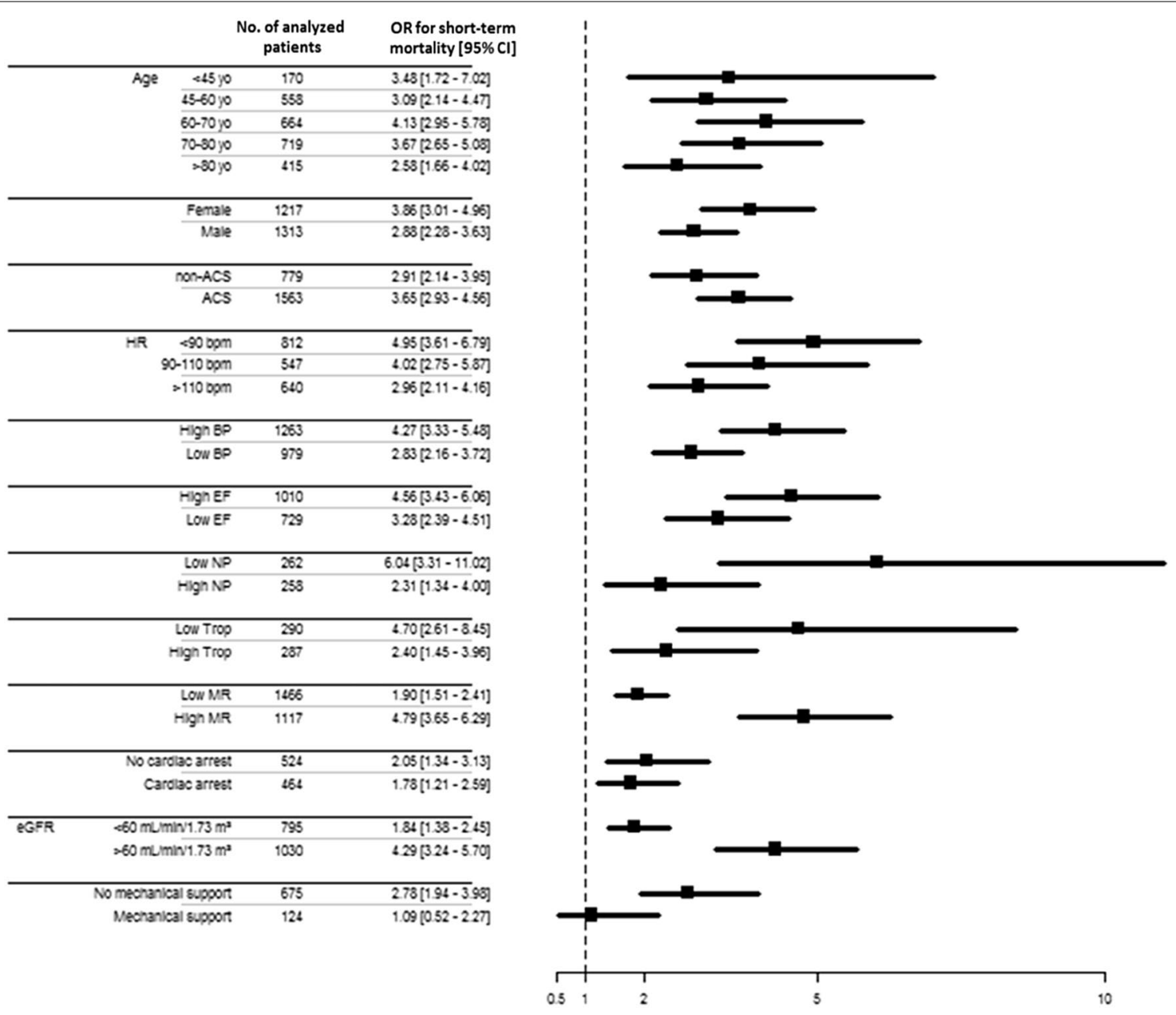

Fig. 5 Forest plot of the meta-analysis of short-term mortality, with subgroup analysis. ACS acute coronary syndrome, HR heart rate, BP blood pressure (low BP, MAP $<65 \mathrm{mmHg}$ or SBP $<90 \mathrm{mmHg}$ ), EF ejection fraction, NP natriuretic peptide, Trop troponin, MR mortality rate. Low/high cutoff was defined as the median value within each cohort

recommended as recently suggested $[3,4,9,11,33,34]$. Concerning cardiogenic shock following cardiac arrest, in patients already on continuous epinephrine, our data suggest that replacing epinephrine with other inotropes and/or vasopressors may be desirable.

Our study has several limitations. First, our analysis included mostly observational studies because of the paucity of randomized trials on the safety effect of epinephrine. In addition to a potential publication bias, we were also dependent on the cooperation of original investigators, not all of whom responded to our request for collaboration. However, our meta-analysis confirmed the result of the recently published OPTIMA CC [11], the only randomized trial comparing epinephrine to norepinephrine. The results of the present meta-analysis are only exploratory. Prospective trials assessing the safety of epinephrine compared to other treatment regimen in cardiogenic shock are urgently needed. Second, we were confronted with many data available issues. This was expected as collaborating authors did not use the same data set in their studies, hindering the adjustment of our analysis for the full cohort. However, adjustment analysis, taking into account the severity of hemodynamic instability, and propensity score matching both confirmed the main result of the meta-analysis. Third, the impact of the quality of the studies on the risk of bias was not assessed in the present meta-analysis as only one of the 16 included cohorts originally aimed to assess the effect of epinephrine on mortality. Fourth, we were not able to collect data on dose or duration of epinephrine therapy or on its combination with other therapies (inotrope, vasopressor, or others). We were not able to assess whether there is a dose-dependent detrimental effect of epinephrine on outcome. However, our study shows that 
epinephrine was consistently associated with worse outcome in almost every study, regardless of illness severity and heterogeneity in CS management. More importantly, our analysis showed that mortality of each study was positively associated with the proportion of CS patients treated with epinephrine. Finally, the primary endpoint (short-term mortality) may appear restrictive and inadequate for the 462 patients resuscitated from cardiac arrest. It would have been interesting to associate neurological recovery. The cerebral performance categories scores (CPC scores) were not available in the database and should be evaluated in further studies.

\section{Conclusion}

Using a large collaborative meta-analysis, our study shows that epinephrine is associated with a threefold increase in risk of mortality in CS. This result highlights the need to perform controlled trials of different drug therapies in CS and supports the need to reconsider the use of epinephrine in future guidelines.

\section{Electronic supplementary material}

The online version of this article (https://doi.org/10.1007/s00134-018-5222-9) contains supplementary material, which is available to authorized users.

\footnotetext{
Author details

1 Department of Anesthesiology and Critical Care, APHP - Saint Louis Lariboisière University Hospitals, University Paris Diderot and INSERM UMR-S 942 Paris, France. ${ }^{2}$ Department of Anesthesiology and Critical Care Medicine, Hôpital Européen Georges Pompidou, Paris, France. ${ }^{3}$ Cardiology Department, University Hospital Brno and Faculty of Medicine, Masaryk University, Brno, Czech Republic. ${ }^{4}$ Emergency Medicine, University of Helsinki and Department of Emergency Medicine and Services, Helsinki University Hospital, Helsinki, Finland. ${ }^{5}$ Heart and Lung Center, University of Helsinki and Helsinki University Hospital, Helsinki, Finland. ${ }^{6}$ Intensive Care Unit, University Hospital Félix Guyon, Saint Denis, France. ${ }^{7}$ CIC-Plurithématique, INSERM, University Hospital of Nancy, Nancy, France. ${ }^{8}$ Intensive Cardiac Care Unit, Florence University Hospital, Careggi, Florence, Italy. ${ }^{9}$ Cardiovascular Department, Hôpital de la Tour, Meyrin-Geneva, Switzerland. ${ }^{10}$ Department of Intensive Care, Austin Hospital, Melbourne, Australia. ${ }^{11}$ Australian and New Zealand Intensive Care Research Centre (ANZIC RC), School of Public Health and Preventive Medicine, Monash University, Melbourne, Australia. ${ }^{12}$ School of Medicine, The University of Melbourne, Melbourne, Australia. ${ }^{13}$ Department of Intensive Care, Royal Melbourne Hospital, Melbourne, Australia. ${ }^{14}$ Division of Nephrology, National University Health System, University Medicine Cluster, Singapore, Singapore. ${ }^{15}$ Cardiology Department, University Hospital of Nancy, Vandoeuvre-lès-Nancy, France. ${ }^{16}$ AMC Heart Center, Academic Medical Center, University of Amsterdam, Amsterdam, The Netherlands. ${ }^{17}$ Department of Medicine/ Cardiology, Heart Center Dresden University of Technology, Dresden, Germany. ${ }^{18}$ Praxisklinik Herz und Gefaesse, Dresden, Germany. ${ }^{19}$ Intensive Care Unit, Faculty of Medicine, University Hospital of Nancy, France, and U1116, Vandoeuvre-lès-Nancy, France. ${ }^{20}$ Department of Anesthesiology and Critical Care Medicine, PhyMedExp, University of Montpellier, INSERM, CNRS, Montpellier, France. ${ }^{21}$ Division of Cardiology, Henry Ford Hospital, 2799W. Grand Blvd - K14, Detroit, MI 48202, USA. ${ }^{22}$ Medical Intensive Care Unit, University Medical Centre Maribor, Ljubljanska, Maribor, Slovenia. ${ }^{23}$ Department of Internal Medicine III, University of Cologne, Cologne, Germany. ${ }^{24}$ Investigation Network Initiative - Cardiovascular and Renal Clinical Trialists, INI-CRCT, Nancy, France.

${ }^{25}$ Emergency Department, University Hospital of Nancy, Nancy, France.

${ }^{26}$ INSERM U1116, University of Lorraine, Nancy, France.
}

\section{Compliance with ethical standards}

\section{Conflict of interest}

AM received lecture fees from Novartis, Orion and Abbott, research grants from Roche and consultant fees from Servier and Sanofi. Other coauthors have no conflicts to declare.

\section{Authors' comment}

One of the two unpublished data set-the one of Basir-was published after data extraction, and is refered as [35].

Received: 23 April 2018 Accepted: 8 May 2018

Published online: 1 June 2018

\section{References}

1. Reynolds HR, Hochman JS (2008) Cardiogenic shock: current concepts and improving outcomes. Circulation 117:686-697. https://doi. org/10.1161/CIRCULATIONAHA.106.613596

2. Prondzinsky R, Unverzagt S, Russ M et al (2012) Hemodynamic effects of intra-aortic balloon counterpulsation in patients with acute myocardial infarction complicated by cardiogenic shock: the prospective, randomized IABP shock trial. Shock 37:378-384. https://doi.org/10.1097/ SHK.0b013e31824a67af

3. Ponikowski P, Voors AA, Anker SD et al (2016) 2016 ESC guidelines for the diagnosis and treatment of acute and chronic heart failure. Rev Esp Cardiol 69:1167. https://doi.org/10.1016/j.rec.2016.11.005

4. Van Diepen S, Katz JN, Albert NM et al (2017) Contemporary management of cardiogenic shock: a scientific statement from the American Heart Association. Circulation 136:e232-e268

5. Mebazaa A, Parissis J, Porcher R et al (2011) Short-term survival by treatment among patients hospitalized with acute heart failure: the global ALARM-HF registry using propensity scoring methods. Intensive Care Med 37:290-301. https://doi.org/10.1007/s00134-010-2073-4

6. Mebazaa A, Motiejunaite J, Gayat E et al (2018) Long-term safety of intravenous cardiovascular agents in acute heart failure: results from the European Society of Cardiology Heart Failure Long-Term Registry. Eur J Heart Fail 20:332-341. https://doi.org/10.1002/ejhf.991

7. Kirsch M, Vermes E, Radu C et al (2008) Impact of preoperative hemodynamic support on early outcome in patients assisted with paracorporeal Thoratec ventricular assist device. Eur J Cardiothorac Surg 34:262-267. https://doi.org/10.1016/j.ejcts.2008.03.057

8. Schreiber W, Herkner $\mathrm{H}$, Koreny $M$ et al (2002) Predictors of survival in unselected patients with acute myocardial infarction requiring continuous catecholamine support. Resuscitation 55:269-276

9. Tarvasmäki T, Lassus J, Varpula M et al (2016) Current real-life use of vasopressors and inotropes in cardiogenic shock-adrenaline use is associated with excess organ injury and mortality. Crit Care 20:208. https //doi.org/10.1186/s13054-016-1387-1

10. Levy B, Perez P, Perny J et al (2011) Comparison of norepinephrine-dobutamine to epinephrine for hemodynamics, lactate metabolism, and organ function variables in cardiogenic shock. A prospective, randomized pilot study. Crit Care Med 39:450-455. https://doi.org/10.1097/CCM.0b013 e3181ffe0eb

11. Levy B, Clere-Jehl R, Legras A, Morichau-Beauchant T, Leone M, Ganster F, Quenot JP, Kimmoun A, Cariou A, Lassus J, Harjola VP, Meziani F, Louis G, Rossignol P, Duarte K, Girerd N, Mebazaa A, Vignon P. Epinephrine versus norepinephrine in cardiogenic shock after acute myocardial infarction. A double-blind, multicenter randomized study. J Am Coll Cardiol. In press.

12. Stewart LA, Clarke M, Rovers M et al (2015) Preferred reporting items for systematic review and meta-analyses of individual participant data: the PRISMA-IPD statement. JAMA 313:1657-1665. https://doi.org/10.1001/ jama.2015.3656 
13. Wells GA, Shea B, O'Connell D et al (2013) The Newcastle-Ottawa scale (NOS) for assessing the quality of nonrandomized studies in meta-analyses. Ottawa Hosp Res Inst. https://doi.org/10.2307/632432

14. Viechtbauer W (2010) Conducting meta-analyses in R with the metafor package. J Stat Softw 36:1-48

15. Gayat E, Pirracchio R, Resche-Rigon M et al (2010) Propensity scores in intensive care and anaesthesiology literature: a systematic review. Intensive Care Med 36:1993-2003. https://doi.org/10.1007/s00134-010-1991-5

16. Zobel C, Adler C, Kranz A et al (2012) Mild therapeutic hypothermia in cardiogenic shock syndrome. Crit Care Med 40:1715-1723. https://doi. org/10.1097/CCM.0b013e318246b820

17. Spinar J, Parenica J, Vitovec J et al (2011) Baseline characteristics and hospital mortality in the acute heart failure database (AHEAD) main registry. Crit Care 15:R291. https://doi.org/10.1186/cc10584

18. Champion S, Gaüzère BA, Vandroux D et al (2014) Dobutamine infusion and absence of pulmonary hypertension are associated with decreased mortality in a cohort of 249 patients with cardiogenic shock. Health 06:2408-2415. https://doi.org/10.4236/health.2014.618277

19. Chua H-R, Glassford N, Bellomo R (2012) Acute kidney injury after cardiac arrest. Resuscitation 83:721-727. https://doi.org/10.1016/j.resuscitat ion.2011.11.030

20. Zannad F, Mebazaa A, Juillière Y et al (2006) Clinical profile, contemporary management and 1-year mortality in patients with severe acute heart failure syndromes: the EFICA study. Eur J Heart Fail 8:697-705. https://doi. org/10.1016/j.ejheart.2006.01.001

21. Gaudard P, Mourad M, Eliet J et al (2015) Management and outcome of patients supported with Impella 5.0 for refractory cardiogenic shock. Crit Care 19:363. https://doi.org/10.1186/s13054-015-1073-8

22. Popovic B, Fay R, Cravoisy-Popovic A, Levy B (2014) Cardiac power index, mean arterial pressure, and Simplified Acute Physiology Score II are strong predictors of survival and response to revascularization in cardiogenic shock. Shock 42:22-26. https://doi.org/10.1097/SHK.0000000000 000170

23. Valente S, Lazzeri C, Crudeli E et al (2012) Intraaortic balloon pump: incidence and predictors of complications in the Florence registry. Clin Cardiol 35:200-204. https://doi.org/10.1002/clc.20975

24. Ouweneel DM, Eriksen E, Sjauw KD et al (2017) Percutaneous mechanical circulatory support versus intra-aortic balloon pump in cardiogenic shock after acute myocardial infarction. J Am Coll Cardiol 69:278-287. https:// doi.org/10.1016/j.jacc.2016.10.022

25. Simonis G, Steiding K, Schaefer K et al (2012) A prospective, randomized trial of continuous lateral rotation ("kinetic therapy") in patients with cardiogenic shock. Clin Res Cardiol 101:955-962. https://doi.org/10.1007/ s00392-012-0484-7

26. Urban P, Stauffer JC, Bleed D et al (1999) A randomized evaluation of early revascularization to treat shock complicating acute myocardial infarction. The (Swiss) multicenter trial of angioplasty for shock-(S)MASH. Eur Heart J 20:1030-1038. https://doi.org/10.1053/euhj.1998.1353

27. Napp LC, Kühn C, Bauersachs J (2017) ECMO in cardiac arrest and cardiogenic shock. Herz 42:27-44. https://doi.org/10.1007/s00059-016-4523-4

28. Huang L, Sun S, Fang $X$ et al (2006) Simultaneous blockade of alpha1and beta-actions of epinephrine during cardiopulmonary resuscitation. Crit Care Med 34:S483-S485. https://doi.org/10.1097/01.CCM.00002 47724.19004.EB

29. Benthem L, van der Leest J, Meeuwsen WP et al (1990) The effect of epinephrine on oxygen consumption, overall energy metabolism, and substrate utilization in rats. Adv Exp Med Biol 277:851-860

30. Vincent J-L, De Backer D (2013) Circulatory shock. N Engl J Med 369:1726-1734. https://doi.org/10.1056/NEJMra1208943

31. Ristagno G, Tang W, Huang L et al (2009) Epinephrine reduces cerebral perfusion during cardiopulmonary resuscitation. Crit Care Med 37:1408-1415. https://doi.org/10.1097/CCM.0b013e31819cedc9

32. Tang W, Weil MH, Sun S et al (1995) Epinephrine increases the severity of postresuscitation myocardial dysfunction. Circulation 92:3089-3093

33. Thiele H, Ohman EM, Desch S et al (2015) Management of cardiogenic shock. Eur Heart J 36:1223-1230. https://doi.org/10.1093/eurheartj/ehv051

34. Schumann J, Henrich EC, Strobl H et al (2018) Inotropic agents and vasodilator strategies for the treatment of cardiogenic shock or low cardiac output syndrome. Cochrane Database Syst Rev. https://doi. org/10.1002/14651858.CD009669.pub3

35. Basir MB, Schreiber T, Dixon S, Alaswad K, Patel K, Almany S, Khandelwal A Hanson I, George A, Ashbrook M, Blank N, Abdelsalam M, Sareen N, Timmis SBH, O'Neill WW (2018) Feasibility of early mechanical circulatory support in acute myocardial infarction complicated by cardiogenic shock: the detroit cardiogenic shock initiative. Catheterization and Cardiovascular Interventions 91(3):454-461 